\title{
NMR Techniques in Metabolomic Studies: A Quick Overview on Examples of Utilization
}

\author{
Joanna Kruk ${ }^{1}\left(\right.$ Marek $^{-}$Doskocz $^{2} \cdot$ Elżbieta Jodłowska $^{1} \cdot$ \\ Anna Zacharzewska ${ }^{1}$ - Joanna Lakomiec ${ }^{1}$. \\ Kornelia Czaja $^{1} \cdot$ Jacek Kujawski $^{1,3}$
}

Received: 19 July 2016/Revised: 10 October 2016/Published online: 2 November 2016

(C) The Author(s) 2016. This article is published with open access at Springerlink.com

\begin{abstract}
Metabolomics is a rapidly developing branch of science that concentrates on identifying biologically active molecules with potential biomarker properties. To define the best biomarkers for diseases, metabolomics uses both models (in vitro, animals) and human, as well as, various techniques such as mass spectroscopy, gas chromatography, liquid chromatography, infrared and UV-VIS spectroscopy and nuclear magnetic resonance. The last one takes advantage of the magnetic properties of certain nuclei, such as ${ }^{1} \mathrm{H},{ }^{13} \mathrm{C},{ }^{31} \mathrm{P},{ }^{19} \mathrm{~F}$, especially their ability to absorb and emit energy, what is crucial for analyzing samples. Among many spectroscopic NMR techniques not only one-dimensional (1D) techniques are known, but for many years two-dimensional (2D, for example, COSY, DOSY, JRES, HETCORE, HMQS), three-dimensional (3D, DART-MS, HRMAS, HSQC, HMBC) and solid-state NMR have been used. In this paper, authors taking apart fundamental division of nuclear magnetic resonance techniques intend to shown their wide application in metabolomic studies, especially in identifying biomarkers.
\end{abstract}

\section{Introduction}

Metabolomics is a rapidly growing branch of science and medicine that aims at identifying new biomarkers of a variety of human diseases and disorders, also investigating them on animal models. It focuses primarily on diseases for which

Joanna Kruk

jkruk@ump.edu.pl

1 Department of Organic Chemistry, Faculty of Pharmacy, Poznan University of Medical Sciences, Grunwaldzka 6 Str., 60-780 Poznan, Poland

2 RootInnovation Sp. z o.o., Jana Matejki 11 Str., 50-333 Wrocław, Poland

3 Foundation for Development of Science and Business on Medical and Exact Sciences Area, Legnicka 65 Str., 54-206 Wrocław, Poland 
currently no definite biomarker is known. The techniques most commonly utilized in metabolomics are: mass spectrometry (MS) as an analytical technique, together with gas or liquid chromatography (GC or LC) as additive methods, or nuclear magnetic resonance (NMR) spectroscopy. Other methods are: UV-VIS (Fig. 1), IR, RAMAN and SEM [1]. Whereas mass spectroscopy measures the ratio of mass to charge of ionized particles, nuclear magnetic spectroscopy takes advantage of the magnetic properties of certain nuclei, such as ${ }^{1} \mathrm{H},{ }^{13} \mathrm{C},{ }^{31} \mathrm{P}$ and others [2-4]. This spectroscopy consists in arousing nuclear spins being located in a magnetic external field through rapid changes of the magnetic field, and then recording of the electromagnetic radiation occurring as a result of occurrences of the relaxation. When a given frequency of the electromagnetic wave is used, only the nuclei with such resonance frequency absorb it. The immediate surroundings of the nucleus affect its resonance frequency (frequency for which pulses have the largest amplitude), thus making it possible to distinguish nuclei, which are surrounded by different atoms in a given compound.

We intend to show wide application of nuclear magnetic resonance techniques in metabolic studies based on crucial division on one-dimensional, two-dimensional, three-dimensional and solid-state NMR (ssNMR) techniques. We also briefly present examples of ${ }^{19} \mathrm{~F}$ NMR spectroscopy techniques from the discussed standpoint; however, it is noteworthy that due to number of literature data regarding this method, this topic will be a goal of further review. To facilitate broadening knowledge about spectroscopy and metabolomics, fundamental abbreviations are presented (Table 1).

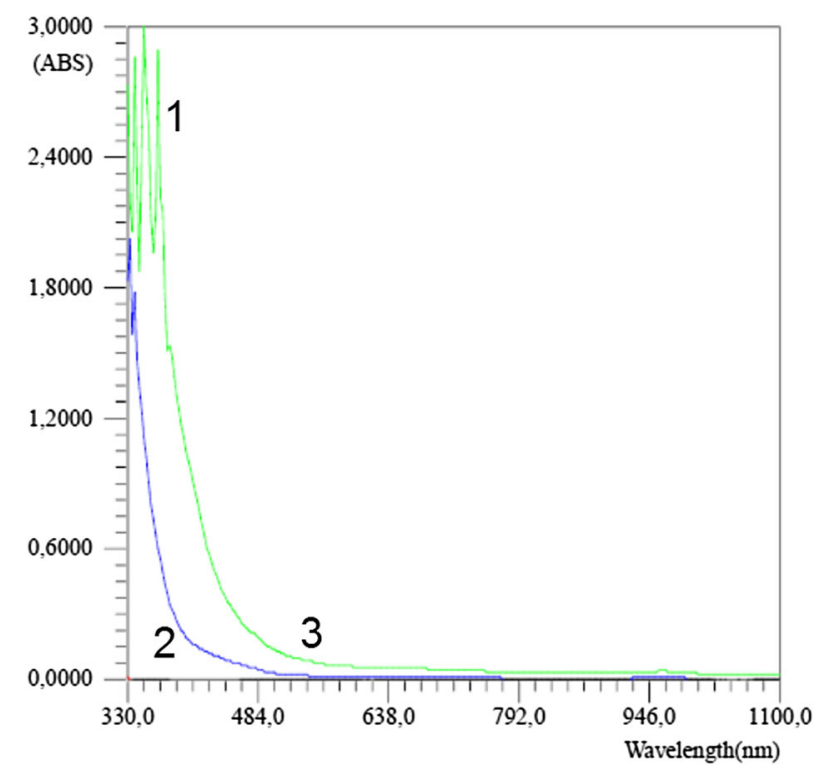

Fig. 1 UV-Vis spectrum of human urine. 1 Water, 2 6-year-old kids, 3 adult. Own researches 
Table 1 List of abbreviations used in current publication

\begin{tabular}{|c|c|}
\hline Abbreviation & Technique \\
\hline NOEPR & $\begin{array}{l}\text { 1D Nuclear Overhauser Effect spectroscopy, Pulse train with Presaturation during } \\
\text { Relaxation and mixing time }\end{array}$ \\
\hline WET & Water suppression Enhanced through T1 effect \\
\hline ES & Excitation sculpting \\
\hline ESCW & $\mathrm{CW}$ on-resonance saturation pulse \\
\hline ESWGL & Adiabatic frequency modulation "wiggly" pulse during the relaxation delay \\
\hline MISSISSIPPI & $\begin{array}{l}\text { Multiple Intense Solvent Suppression Intended for Sensitive Spectroscopic Investigation } \\
\text { of Protonated Proteins, Instantly }\end{array}$ \\
\hline CPMG & Carr-Purcell-Meiboom-Gill \\
\hline HRMAS & High-Resolution Magic-Angle Spinning \\
\hline PASS & Phase-Adjusted Spinning Sidebands \\
\hline PHORMAT & PHase-cORrected Magic-Angle Turning \\
\hline MACS & Magic-Angle Coil Spinning \\
\hline ERETIC & Electronic REference To access In vivo Concentrations \\
\hline $\mathrm{CP}$ & Cross-Polarization \\
\hline DEPT & Distortionless Enhancement by Polarization Transfer \\
\hline $\begin{array}{l}\text { q-MAS } \\
\text { PGSE }\end{array}$ & Magic-Angle Spinning of the Q-vector in Pulsed-Gradient Spin-Echo \\
\hline
\end{tabular}

\subsection{One-Dimensional Techniques}

The most popular NMR technique is ${ }^{1} \mathrm{H}$ NMR based on ${ }^{1} \mathrm{H}$ nucleus because of their abundance in nature (over 99.98\%) [5], low relaxation time and an appreciable nuclear spin.

Because this method has been commonly used in metabolomics of different biofluids for years, there are numerous emerging techniques involving NMR that are particularly useful in this area $[2,3]$. There are many reviews concerning the latest advances in this branch of science [4, 6], but to the authors' knowledge, there is none regarding the types of NMR techniques and approaches used for metabolomic studies [7, 8], and the authors aim at filling this gap. Moreover, we want to show why these techniques were introduced, what they help to achieve and which challenges they help to overcome. Apart from ${ }^{1} \mathrm{H}$ NMR, the techniques employing other nuclei will also be included, such as ${ }^{13} \mathrm{C}[9],{ }^{31} \mathrm{P}[10],{ }^{43} \mathrm{Ca}[11]$.

NMR spectroscopy has numerous advantages listed in Scheme 1. However, it is capable of detecting the compounds given above micromolar concentrations. To perform the analysis, liquid-state NMR requires an addition of an external standard; for example, tetramethylsilane (TMS) or 4,4-dimethyl-4-silapentane-1-sulfonate (DSS) in case of using water as solvent or octadecanoic acid and methyl octadecanoate for fatty acids and theirs derivatives [12-14]. To perform the quantitative analysis, for example, method utilizing the area per proton (determined by integration) [14], LCModel [15] or OPLSA-DA strategy [16] is used. Quantitative analysis is somewhat more challenging in ssNMR, nevertheless, it is 
Advantages of NMR spectroscopy as an analytical method

- no need for preceding separation of purification methods

- detects both hydrophilic and lipophilic metabolites

- allows for quantitative analysis

- fast method (1-dimensional techniques, excluding solidstate NMR)

- requires small amounts of samples

- non-invasive and non-destructive

- reproducible

Scheme 1 Modified according to Refs. [2-4, 6-13, 20-22, 25, 73-76]

also viable. The examples of using HRMAS technique in intact brain tissue [17] or biopsies from patients suffering from breast cancer [18] analyses show the plenty of other application. Moreover, the detection of metabolites is relatively fast in onedimensional NMR (however, this does not adhere to most ssNMR techniques). Furthermore, this approach requires only small amounts of samples, which is crucial in metabolomics, insofar as usually only small amounts of biofluids or tissues are available. In addition, it is not invasive and destructive, which means that after analysis tissues could be used for further analyses (biofluids as well, but only if the external standard in liquid-state NMR and $\mathrm{pH}$ adjustment would not impact the results). Therefore, the ${ }^{1} \mathrm{H}$ NMR spectroscopy is used in metabolomics primarily inasmuch as enable quantitative, reproducible and usually relatively analysis $[15,16,19]$.

One-dimensional NMR spectroscopy is the one that is most commonly used, but certain problems can be encountered during such analysis as ${ }^{1} \mathrm{H}$ NMR spectra contain many overlapping peaks. One compound that causes problems is glucose. In case of this sugar, strong peaks between 3.2 and $4.0 \mathrm{ppm}$ overshadow other signals in this part of the serum or urine spectrum. However, these difficulties can be overcome for instance by an "Add to Subtract" background subtraction method [20]. According to the obtained results, the glucose signals can be decreased by 98\%, which allows to obtain the otherwise invisible data. The procedure involves acquiring a second spectrum after adding a small amount of concentrated glucose solution to the sample. Then the differences between the NMR spectra with and without added glucose can be computed. Other methods that allow to remove glucose signals without influencing other signals are background subtraction and separation techniques prior to the NMR analysis [20-23].

Not only glucose or proteins [23,24] signals can overshadow other peaks- the most abundant compound in the NMR metabolomics is water, the main component of biofluids and tissues. Therefore, water suppression is crucial to obtain interpretable spectra and there are numerous water suppression and water presaturation techniques. In a comparison of NOEPR (1D NOESY, Nuclear Overhauser Effect Spectroscopy, Pulse train with Presaturation during Relaxation and mixing time), WET (Water suppression Enhanced through T1 effect) and excitation sculpting (accompanied by either a $\mathrm{CW}$ on-resonance saturation pulse, $\mathrm{ESCW}$, or an adiabatic 
frequency modulation "wiggly" pulse during the relaxation delay, ESWGL), it was concluded that ESCW, ESWGL, NOEPR and ES methods obtain great water suppression with high reproducibility. WET yielded distinctly worse results [21]. It is worth mentioning that NOESY technique is the most popular and enables optimization of process. Other solvent suppression techniques are being developed, such as Multiple Intense Solvent Suppression Intended for Sensitive Spectroscopic Investigation of Protonated Proteins, Instantly (MISSISSIPPI), which consists of gradient and saturation pulses [22]. Currently, due to the variability in the quality of water suppression, the water peaks are present in the spectra and, therefore, the region of water resonance is not included in the metabolomic analysis (approximately 4.50-5.00 ppm). The emerging water suppression techniques might change it and make it possible to retrieve data also from this part of the spectrum [22].

1D spectra are also acquired with the Carr-Purcell-Meiboom-Gill (CPMG) pulse sequence to decrease broad signals from proteins and lipoproteins because of their relatively long transverse relaxation times [23, 25]. Thus, the signals from compounds with low molecular weight are not overshadowed by signals of macromolecules. An example of mentioned spectrum is given in Fig. 2.

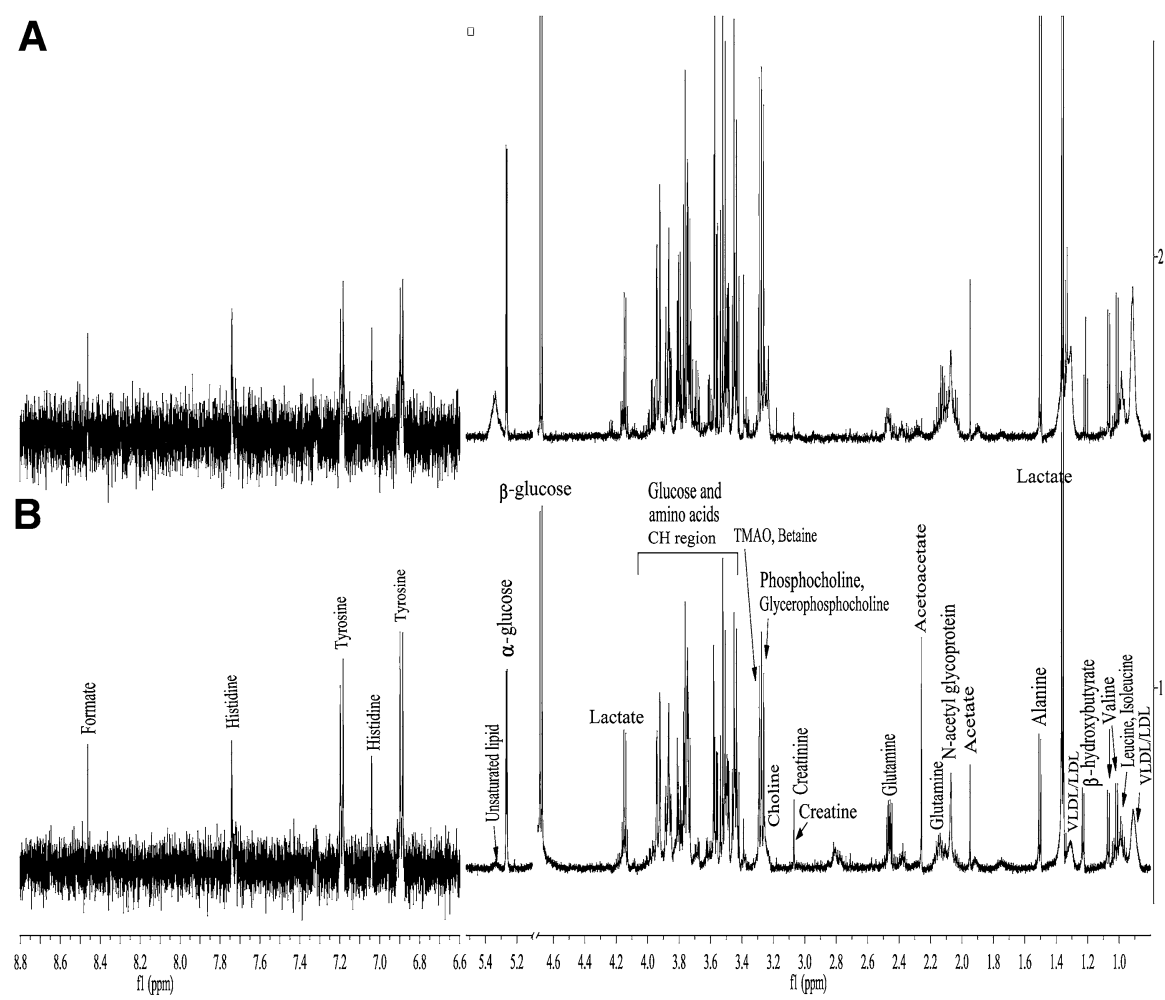

Fig. 2 Example of one-dimensional Carr- Purcell-Meiboom-Gill (1D - CPMG) 1H NMR spectra of serum spectra from: a healthy patient, b patient suffering from esophageal cancer showing key metabolites. Modified according to [25] 


\subsection{Two-Dimensional (2D) Techniques}

The problems that arise from signal overlap can be partly overcome by employing two-dimensional NMR spectroscopy. It allows to determine the peak intensity and its properties, such as the spin multiplicity and coupling constant, even if in 1D spectra it is overshadowed by a stronger signal. Table 2 outlines a concise comparison of 1D and 2D NMR techniques. There are a number of 2D NMR methods that are particularly commonly used in metabolomics to determine the presence and concentrations of otherwise undetectable compounds or confirm peak assignment by spin connectivities [26]. In Table 3 are depicted the most commonly used 2D NMR techniques with their application in metabolomics. So far, there is not known a fast and automatic methodology of signal' deconvolution and times of measurements are not acceptable.

It is noteworthy that the difficulties encountered during analysis depend on properties of biofluid tested. The most widely used biofluids in metabolomics are serum/plasma and urine (Figs. 3, 4). They are relatively easy to obtain and their collection is relatively non-invasive. Additionally, the cerebrospinal fluid (CSF) is also examined [27], but on a smaller scale because of the invasiveness of the lumbar puncture. Herein, the fact that NMR analysis requires only small amounts of samples is particularly important, inasmuch as bigger amounts of CSF would be extremely difficult to obtain without side effects for the patient. On the other hand, this small amount of sample is sufficient for detecting crucial substances (Fig. 5) [28].

Appropriate identification of compounds and determination of their concentrations is of utmost significance. Furthermore, also a dataset of 'control' NMR biofluid results needs to be gathered so as to have a reference group that can be compared to those with a particular disease. It is difficult, inasmuch as compounds of low molecular weight can easily be disturbed by a number of factors, not only a given disease or treatment. Therefore, it is crucial to establish the NMR metabolome

Table 2 Comparison of parameters of 1D and 2D NMR techniques

\begin{tabular}{|c|c|c|}
\hline Parameter & $1 \mathrm{D}$ & $2 \mathrm{D}$ \\
\hline $\begin{array}{l}\text { Degree of overlap for } \\
\text { quantitative analysis }\end{array}$ & Higher & Lower \\
\hline $\begin{array}{l}\text { Sensitivity to pulse } \\
\text { imperfections }\end{array}$ & $\begin{array}{l}\text { Lower (lower signal } \\
\text { to noise ratio) }\end{array}$ & Higher \\
\hline $\begin{array}{l}\text { Number of factors } \\
\text { influencing peak }\end{array}$ & Lower & Higher (e.g., J-coupling or relaxation time) \\
\hline Calibration procedure & $\begin{array}{l}\text { One for the whole } \\
\text { experiment }\end{array}$ & $\begin{array}{l}\text { Individual for each compound (for quantitative } \\
\text { analysis-peaks ratio does not reflect the } \\
\text { concentration ratio directly) }\end{array}$ \\
\hline Experiment duration & Shorter & Longer \\
\hline $\begin{array}{l}\text { Efficacy (particularly for } \\
\text { small molecules) }\end{array}$ & Lower & Higher \\
\hline
\end{tabular}

Modified according to Refs. [26, 55] 


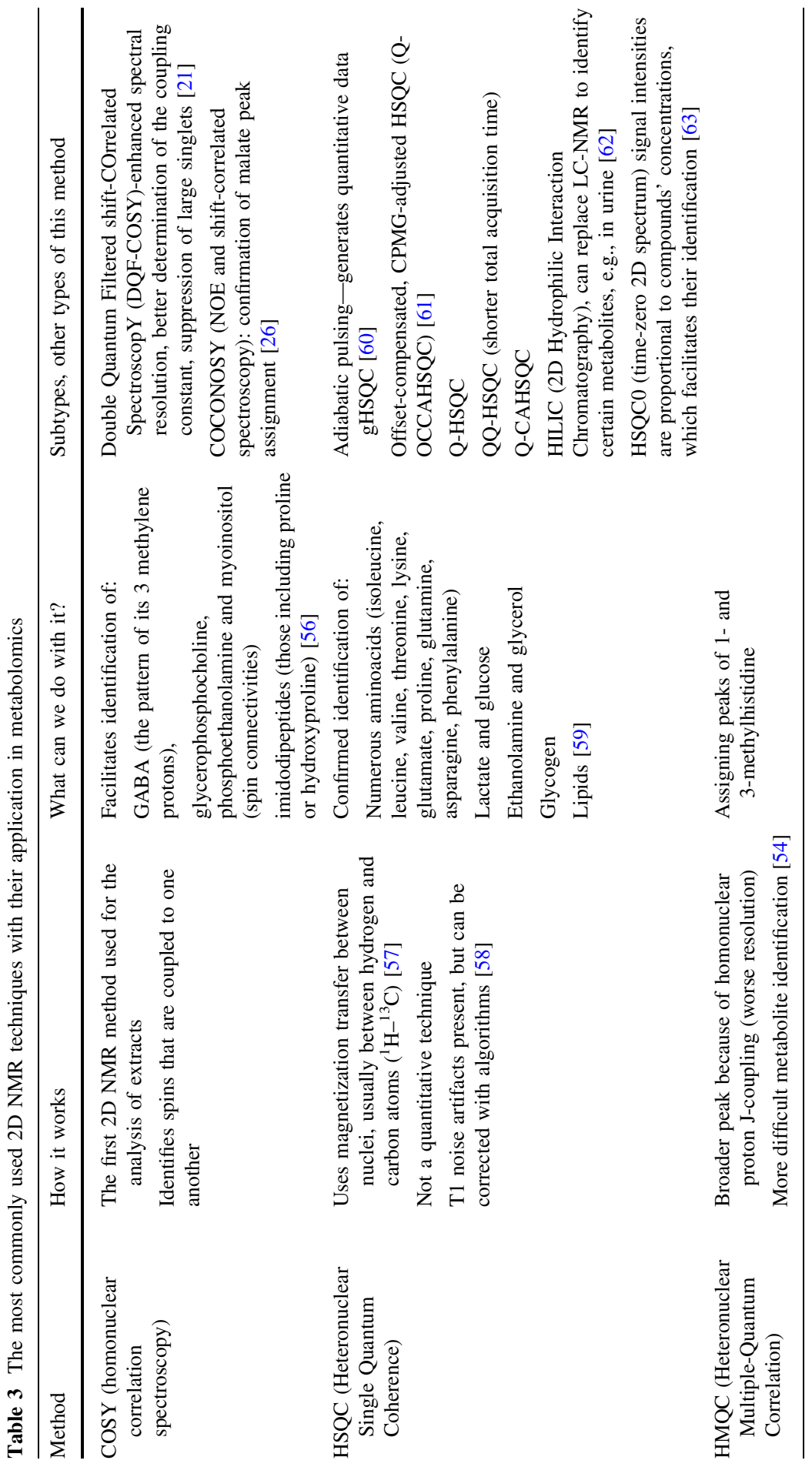




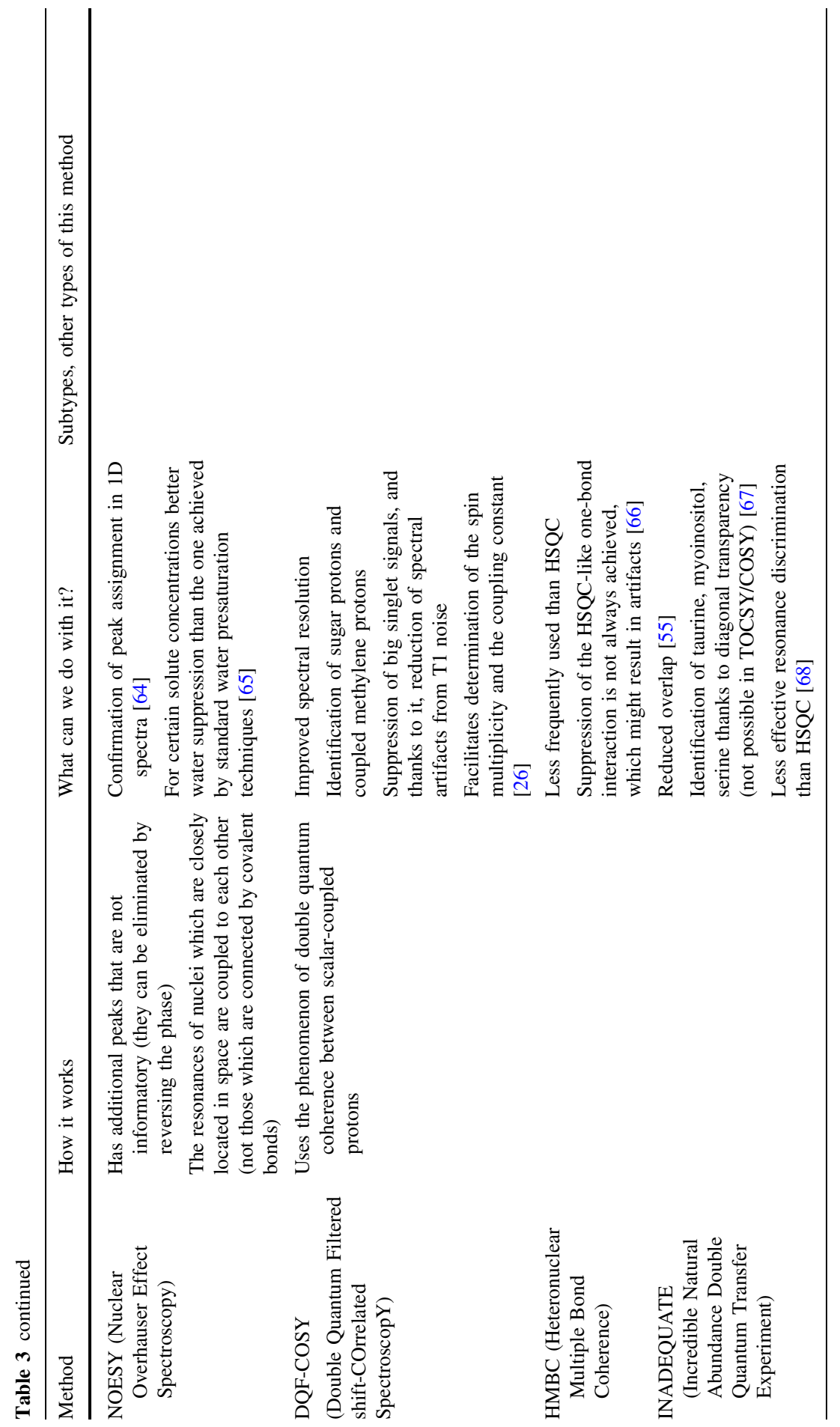




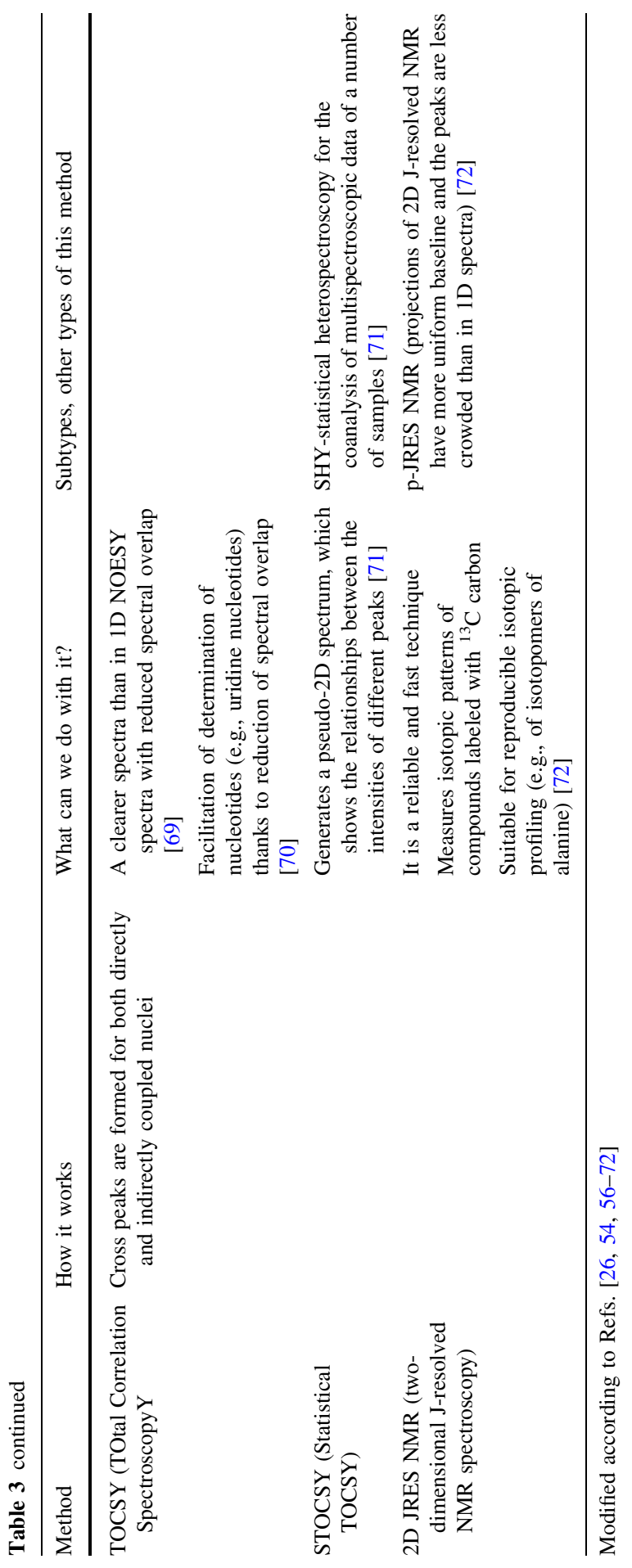




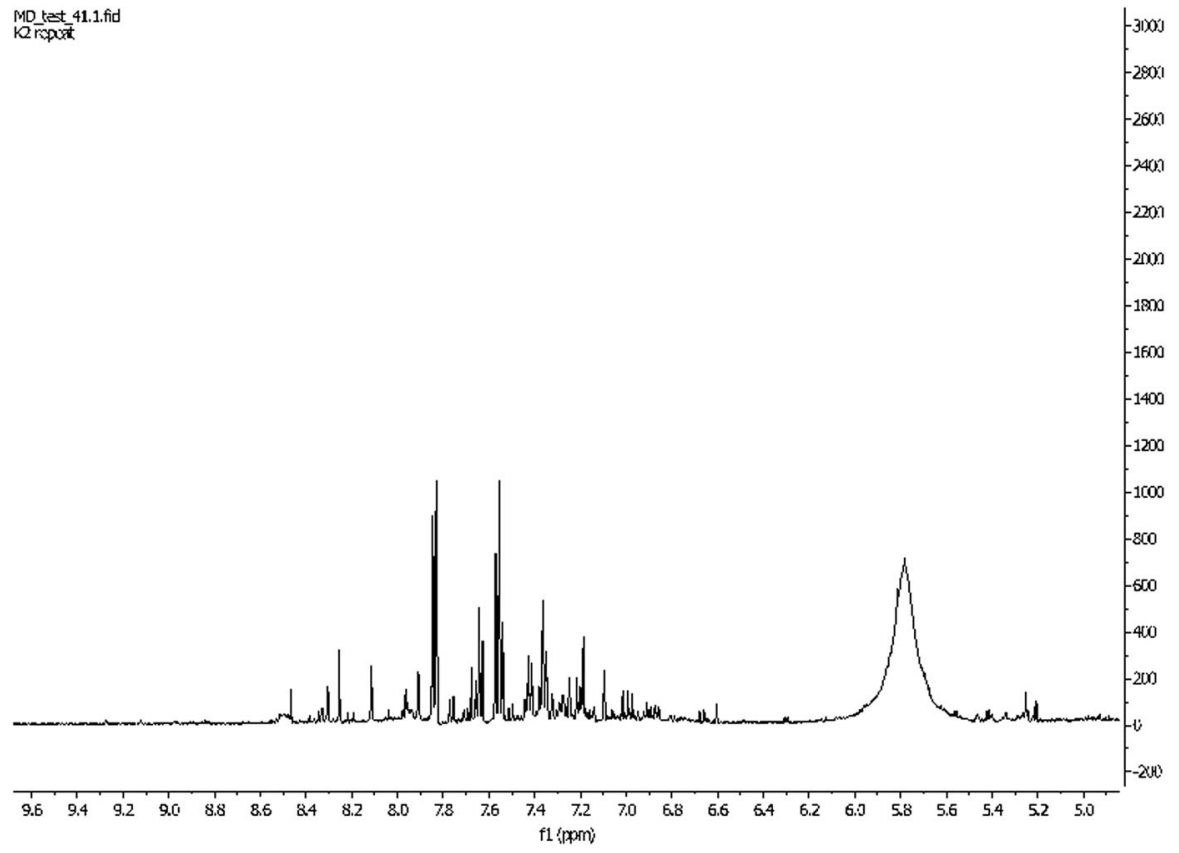

Fig. 3 1H NMR spectrum of human urine. Patient treated by cisplatin. Own researches

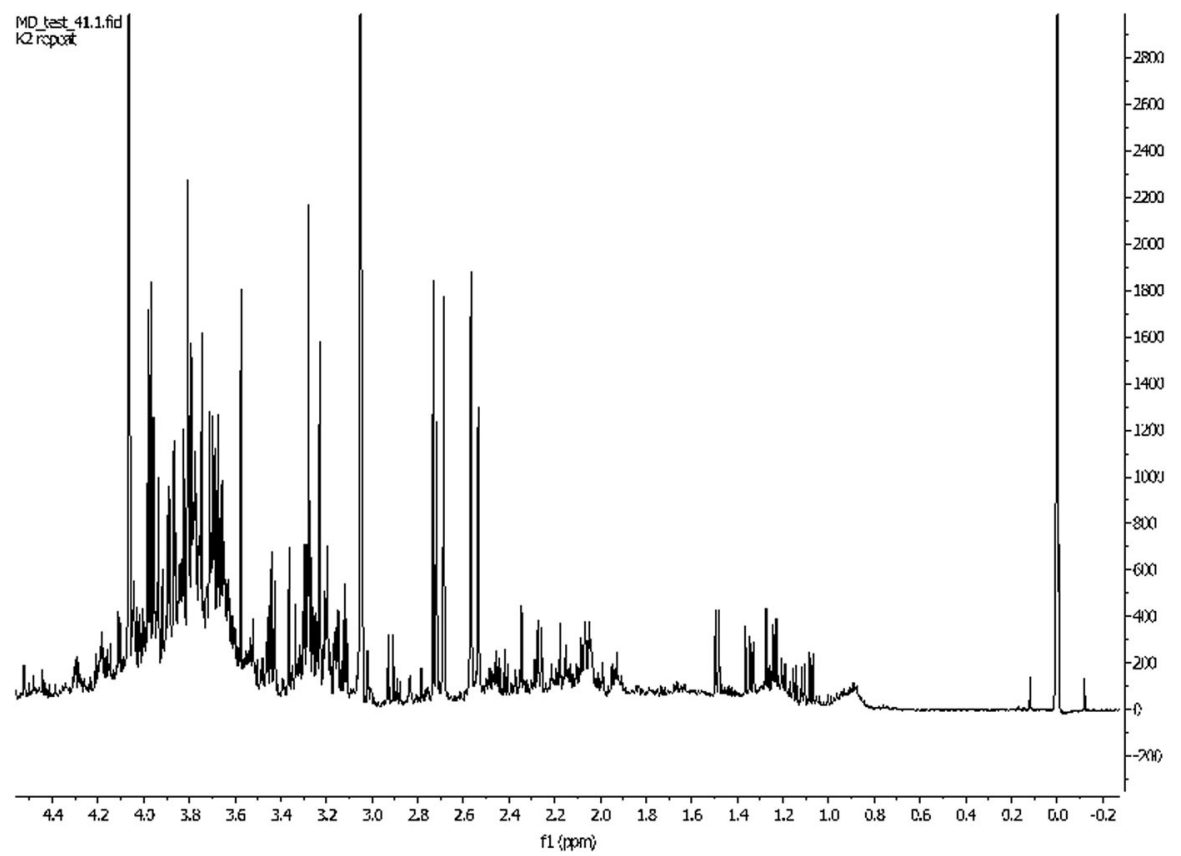

Fig. 4 1H NMR spectrum of human urine extension. Patient treated by cisplatin. Own researches 


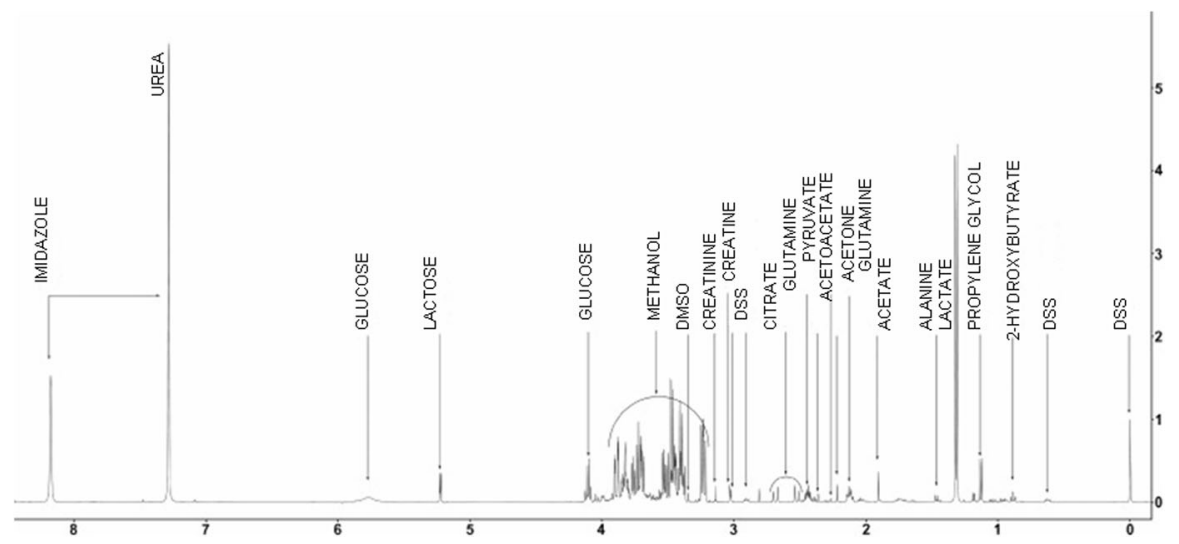

Fig. 5 1H NMR spectrum of human CSF. Modified according to Ref. [28]

of human serum, urine and the cerebrospinal fluid, which is primarily done using 1D NMR techniques [28-30].

By NMR techniques it is possible to identify the most compounds in the metabolome of, for example, urine, blond, saliva, sweat, tears, the waters (Figs. 6, 7) and CSF. Generally, the number of identified compounds is higher in comparison to other techniques, such as gas chromatography-mass spectrometry (GC-MS) and high-performance liquid chromatography (HPLC) [31]. For instance, both for the metabolome of CSF and urine NMR detected the most compounds, with the runnerup being GC-MS. NMR is also useful in investigating the serum metabolome [29]. Therefore, it seems to be the most appropriate tool for general metabolomic analyses, despite its sensitivity only to compounds above micromolar concentrations [28]. An additional advantage of using NMR for ultrafiltered serum metabolomics is the relative simplicity of the spectra and, therefore, lack of difficulties with peak assignment [29].

Urine metabolome was also investigated on fractions from solid-phase extraction (SPE), with the NMR spectra obtained using a 1D-NOESY pulse sequence with presaturation [30]. There, SPE allowed to obtain five different fractions that contained compounds with different polarity. Whereas the first fraction contains the most polar metabolites, the fifth one contains the least polar ones. As urine primarily consists of polar compounds, the most metabolites were identified in the first fraction and the fewest in the last three ones (almost seven times fewer than in the first fraction).

Additional information on the metabolome of urine can be obtained by means of proton decoupled $13 \mathrm{C}\{1 \mathrm{H}\} \mathrm{NMR}$ spectroscopy by aiding peak assignment, difficult in 1D NMR spectra because of peak overlap [32]. A further advantage of this technique is lack of water signals. Therefore, no water suppression is necessary in this approach. On the other hand some disadvantages, such as low sensitivity and long time of experiment, can be pointed out. 


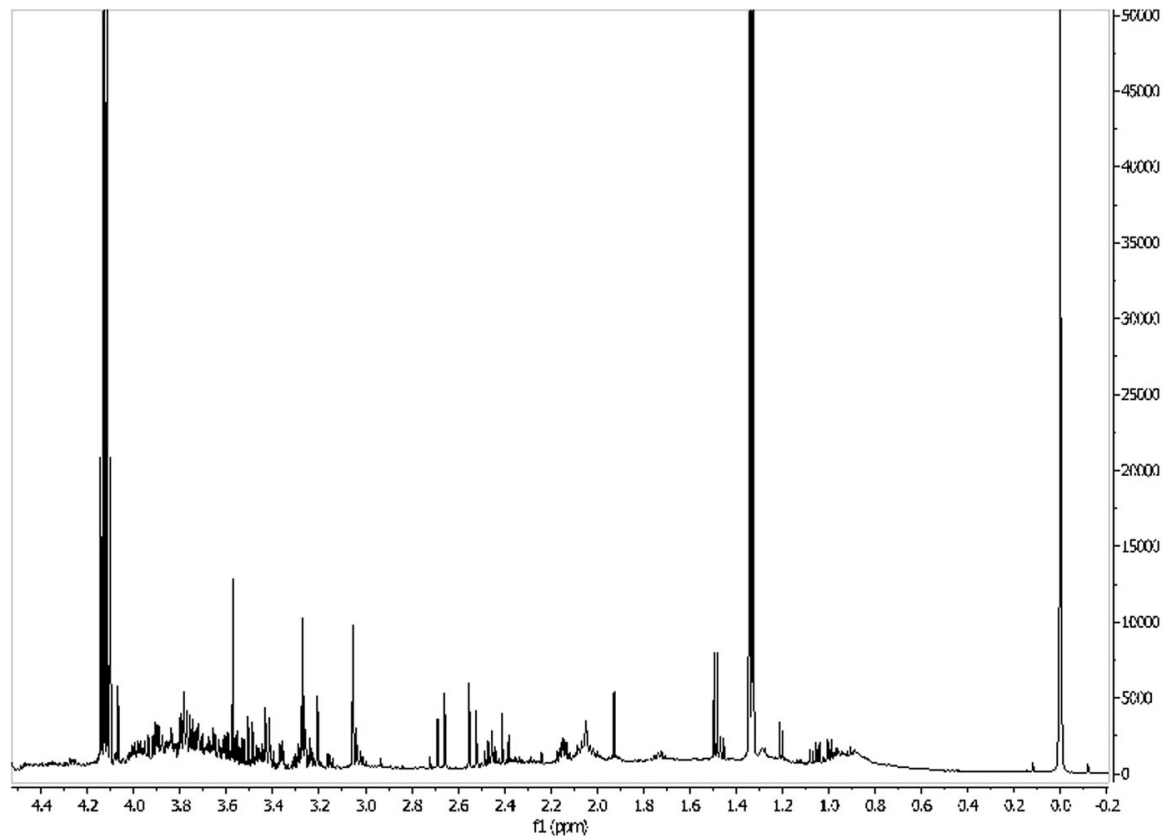

Fig. 6 1H NMR spectrum of the human waters (0-5 ppm). Own researches

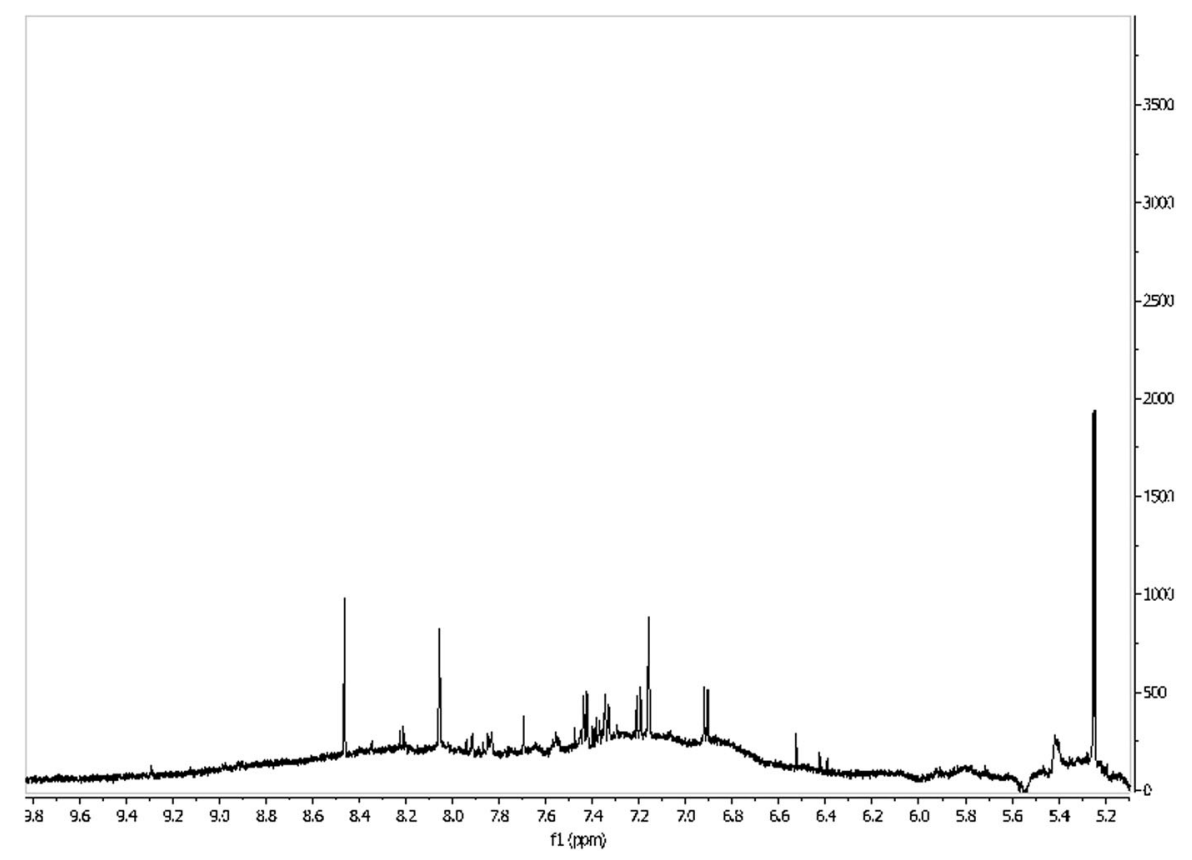

Fig. 7 1H NMR spectrum of the human waters (5-10 ppm). Own researches 


\section{Solid-State NMR (ssNMR)}

Apart from body fluids and tissue extracts (Fig. 8), metabolomics also allows to examine tissue samples, but separate methods have to be used then, such as ssNMR. The advantages of such spectra is the fact that they require little preparation and they retrieve results comparable to those obtained in NMR of considerably more time-consuming tissue extracts. Furthermore, ssNMR is a non-destructive technique and require small tissue samples. Being non-destructive is particularly important in solid-state NMR as it means that after NMR analysis the tissue can be sent for histopathology examination. Obviously, such spectra comprise numerous different peaks and, therefore, 2D NMR techniques also have to be used. However, in solidstate spectra due to dipolar coupling and chemical shift anisotropies, the obtained signals are broadened and, therefore, the signal overlap is increased and they are more difficult to identify. At first, these difficulties were overcome by isotope labeling (particularly in collagen research); nevertheless, it was a costly and timeconsuming method. This is why currently in solid-state experiments, high-resolution magic-angle spinning (HRMAS) spectroscopy is used. It decreases line broadening by rotating the sample at the angle of $54.74^{\circ}$ (the 'magic angle') with respect to the external magnetic field, thus eliminating the anisotropic interactions. It is necessary to use high spinning rates because they have to be higher than or similar to the interaction strength: and especially the dipolar couplings between two hydrogen atoms are quite strong. When lower spinning rates are used, a series of narrow peaks

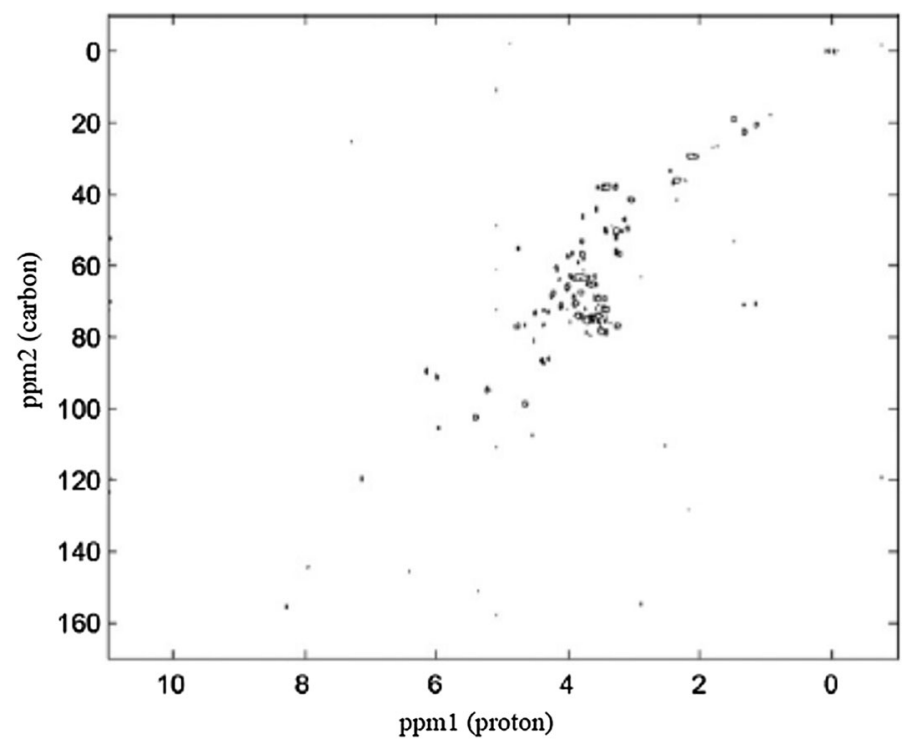

Fig. 8 Example of 2D 1H, 13C HSQC NMR spectrum of biological sample - an extract of fish eggs. Modified according to [35] 
is obtained, separated by equal intervals (equal to multiples of the applied frequency of rotations) [33].

HRMAS techniques allow to achieve better resolution; however, the factors influencing line broadening are highly dependent on the material structure and enable, for example, investigation of bone mineralization [33]. This is why there are few methods that make it possible to conduct recoupling of the anisotropic Hamiltonians and to separate the anisotropic and isotropic interactions, thanks to which more comprehensive data can be obtained that inform us about the material structure [33].

Nevertheless, the spinning in MAS may cause cell and tissue destruction both by rotations and an increase of temperature, and thus impact the measurements. This is why in cases of particularly vulnerable specimens, slow MAS can be used. Obviously, then an additional method must be used to suppress the spinning sidebands, which is normally achieved by fast MAS. Such methods are phaseadjusted spinning sidebands (PASS) and phase-corrected magic-angle turning (PHORMAT). They can be used with magic-angle coil spinning (MACS) to examine small samples with high sensitivity [75].

A challenge, not encountered in NMR of solutions, presents itself in solid-state NMR - quantification of metabolites. In solid-state NMR, it is very difficult or even impossible to add an exact amount of a reference compound. Nonetheless, a method was developed that makes it possible to overcome this obstacle, namely ERETIC (Electronic REference To access In vivo Concentrations). Since its development, it has become widespread in HRMAS NMR as a method that allows to quantify the detected metabolites, e.g., in brain tissue examinations or breast cancer biopsies $[17,18]$.

Apart from tissue samples, such as prostate, cancer biopsies and other organs, also bone and cartilage are researched using HRMAS spectroscopy. Particularly for bone, because of its high phosphate content, cross-polarization HRMAS spectroscopy is used to obtain ${ }^{31} \mathrm{P}$ spectra of better resolution. It uses magnetization transfer from abundant nuclei (such as ${ }^{1} \mathrm{H}$ ) to those less abundant (for example ${ }^{31} \mathrm{P}$ ) via dipolar couplings to enhance the signals from the less numerous ones. However, as was mentioned, fast spinning rate decreases heteronuclear dipolar couplings (such as those between ${ }^{1} \mathrm{H}$ and ${ }^{31} \mathrm{P}$ atoms) - which impairs $\mathrm{CP}$. This way, signals from atoms other than hydrogen that do not have strong couplings to hydrogen nuclei can be eliminated [35]. Because of these relationships, the signal intensity is dependent on the time during which the polarization transfer takes place. This is why in such experiments signal intensity must be compared over a variety of contact times, and not only for its fixed value. Such investigations were carried out considering the phosphorus components and their structure in bone (the graph of intensity vs. contact time is strongly dependent on the material structure) [36-39] and bone implants [33] (Fig. 9). Cross-polarization can be improved using multiple cross-polarization pulse sequences, which considerably shorten the acquisition time [76].

The time required to obtain the spectra in ssNMR can be decreased, e.g., using paramagnetic doping. Then an addition of a solution of copper (II) ions to powdered tissues containing collagen prior to ${ }^{13} \mathrm{C}$ CP MAS resulted in a shortening of the 


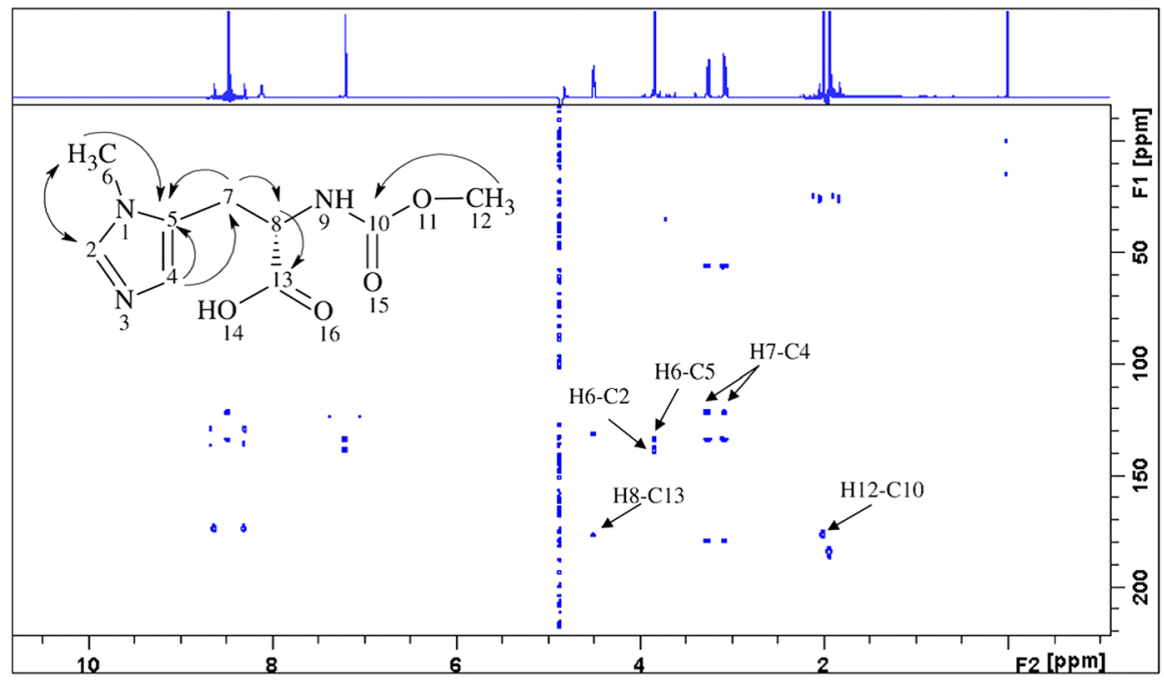

Fig. 9 Example of proton-carbon cross-correlation shown in the HMBC two-dimensional NMR spectrum. Modified according to [54]

hydrogen spin-lattice relaxation time and thus shortened the time needed to acquire the spectrum (because it is highly dependent on this relaxation time). It did not impair the spectral resolution [41].

Apart from CP, also distortionless enhancement by polarization transfer (DEPT) can be applied to improve MAS NMR sensitivity. In liquid-state NMR, it is used to distinguish signals of methyl, methylene and methine groups in ${ }^{13} \mathrm{C}$ NMR spectra. When compared to other techniques, this solid-state method only enhances the signals of compounds of low molecular weight, whereas lipid molecule signals are primarily improved when using the $\mathrm{CP}$ technique because of their low mobility in ${ }^{13} \mathrm{C}$ MAS [42].

With HRMAS it is also possible to measure the diffusion coefficient and relaxation times (so-called $T_{1}$ and $T_{2}$ ). Due to these parameters, signals of low molecular weight compounds can be eliminated because of their longer relaxation time $T_{1}$. Then, lipid signals are enhanced and easier to interpret without using timeconsuming 2D NMR methods. Therefore, diffusion-weighted pulse sequences are a different approach which makes it possible to identify mobile lipid resonances without the overlap with peaks of low molecular weight metabolites [43]. A conjoint measurement of apparent diffusion coefficients and $T_{2}$ can also be measured when one aims at enhancing the peaks of low molecular weight compounds. Then for this purpose an additional gradient spin-echo sequence might be used [44].

New, emerging techniques include comprehensive-multiphase NMR (CMPNMR), which allows to investigate structures present in each phase and the interaction between the phases. So far, it has been investigated with soil samples, but it might prove to be a great tool in tissue examination, especially to study the complex interactions between the different tissue components (such as the blood cells and plasma) [45]. Another technique is q-MAS PGSE NMR (magic-angle 
spinning of the q-vector in pulsed-gradient spin-echo NMR), which is used to examine the pores of different materials by investigating the diffusion of water, without the contribution of anisotropic interactions (they are nullified). Furthermore, comparing q-MAS PGSE NMR and PGSE NMR results makes it possible to determine whether microscopic diffusion anisotropy is present in the examined system. In metabolomics, it might find applications in researching the structure of axons [46].

\section{$3{ }^{19}$ F NMR Spectroscopy in Metabolomic Studies}

In our paper, we described some ${ }^{1} \mathrm{H}$ NMR spectroscopy applications; nevertheless, the progress of ${ }^{19} \mathrm{~F}$ spectroscopy approaches in metabolomics requires attention herein. The nuclei of ${ }^{19} \mathrm{~F}$ is characterised by gyromagnetic ratio almost equal to that of the proton and broader range of chemical shift. Due to connection between metabolomics and pharmaceuticals studies, we would like to indicate some achievements [47-53].

An experiments using glioma model (similarity to human glioblastoma) demonstrate that ${ }^{19} \mathrm{~F}$ MRI in combination with ${ }^{1} \mathrm{H}$ MRI can selectively map the bio-distribution of ${ }^{19} \mathrm{~F}-\mathrm{BPA}$ (boronophenylalanine). The ${ }^{19} \mathrm{~F}$ BPA monitoring uptake in tumors by ${ }^{19} \mathrm{~F}$ imaging indicates the ${ }^{19} \mathrm{~F}$ MRI as a tool of better understanding and investigating the pharmacokinetics of fluorinate-containing drugs. The results of experiments give information about optimal timing for neutron irradiation. In boron neutron capture therapy (BNCT), the exposure time is very important and conclusions from quoted experiment can be useful while conducting therapy [47].

${ }^{1} \mathrm{H},{ }^{19} \mathrm{~F},{ }^{13} \mathrm{C}$ and ${ }^{10} \mathrm{~B}$ magnetic resonance spectroscopy for another boron neutron capture therapy agent, an ${ }^{19} \mathrm{~F}$-labeled, ${ }^{10} \mathrm{~B}$-enriched $p$-boronophenylalanine-fructose complex ( ${ }^{19} \mathrm{~F}$-BPA-fr) is also reported [48]. The aim of the cited study was a reaction yield optimization for the synthesis and the complexation of the BNCT agent. In addition, the feasibility of using ${ }^{19} \mathrm{~F}-\mathrm{MRS}$ to perform pharmacokinetic studies of the ${ }^{19} \mathrm{~F}-\mathrm{BPA}-\mathrm{fr}$ complex was proven [49].

Moreover, application of ${ }^{19} \mathrm{~F}$ NMR spectroscopy in gene therapy is reported, which is limited by difficulties in assessing the success of transfection in terms of spatial extent, gene expression and longevity of expression [49]. Cui et al. prepared the molecular and ${ }^{19} \mathrm{~F}$ NMR characteristics of PFONPG (4-fluoro-2-nitrophenyl- $\beta$ D-galactopyranoside) in solution, blood and prostate tumor cells and showed new possibilities into developments of the gene therapy [49].

Due to the popularity of ${ }^{19} \mathrm{~F}$ spectroscopy in environmental studies and metabolic screening of new isolated organisms, it was used in exploring the aerobic microbial degradation [50]. By analyzing reaction of fluorophenols, the potential of ${ }^{19} \mathrm{~F}$ biodegradation studies was proven. Other studies explore the toxicity of a fluorinelabeled derivative of ascorbic acid (F-ASA), a major antioxidant, by measuring in vitro and in vivo accumulation of F-ASA, fluoro-dehydroascorbate or fluoro-2,3diketogulonate and their degradation products [51]. The importance of such discoveries will be noticed when we make ourselves aware that a lot of drugs 
contain the fluorine atom in their structure. Many anesthetics, chemotherapeutic agents and molecules with high oxygen solubility for respiration and blood substitution can be monitored by MRS techniques, as well as by fluorine $\left({ }^{19} \mathrm{~F}\right) \mathrm{MRI}$ [52]. It is worth to mention that the application of ${ }^{19} \mathrm{~F}$ spectroscopy techniques in the specific targeting, imaging of cellular surface epitopes, cell tracking of endogenous macrophages or injected immune cells is reported as well [52].

Compared to traditional attempt at exploring new biologically active compound, another approach is possible thanks to fluorine NMR-based assay $n$-FABS ( $n$ fluorine atoms for biochemical screening), which enables screening and identification of inhibitors for a specific enzymatic target [53]. Due to easy setup, versatility and lack of interfering signals, this method might be widely applicable and should facilitate the identification and characterization of small molecule inhibitors for example of the membrane-bound serine amidase or fatty acid amide hydrolase [53].

\section{Conclusions}

Since years an enormous development of nuclear magnetic resonance has been observed and many explored techniques have been used in metabolomic studies. Among advantages of 1D techniques applied in metabolomics, employing nuclei such as ${ }^{13} \mathrm{C},{ }^{31} \mathrm{P},{ }^{43} \mathrm{Ca}$, possibility of quantitative analysis, needles of only small amounts of samples and obtaining excellent quality of spectra thanks to solvent

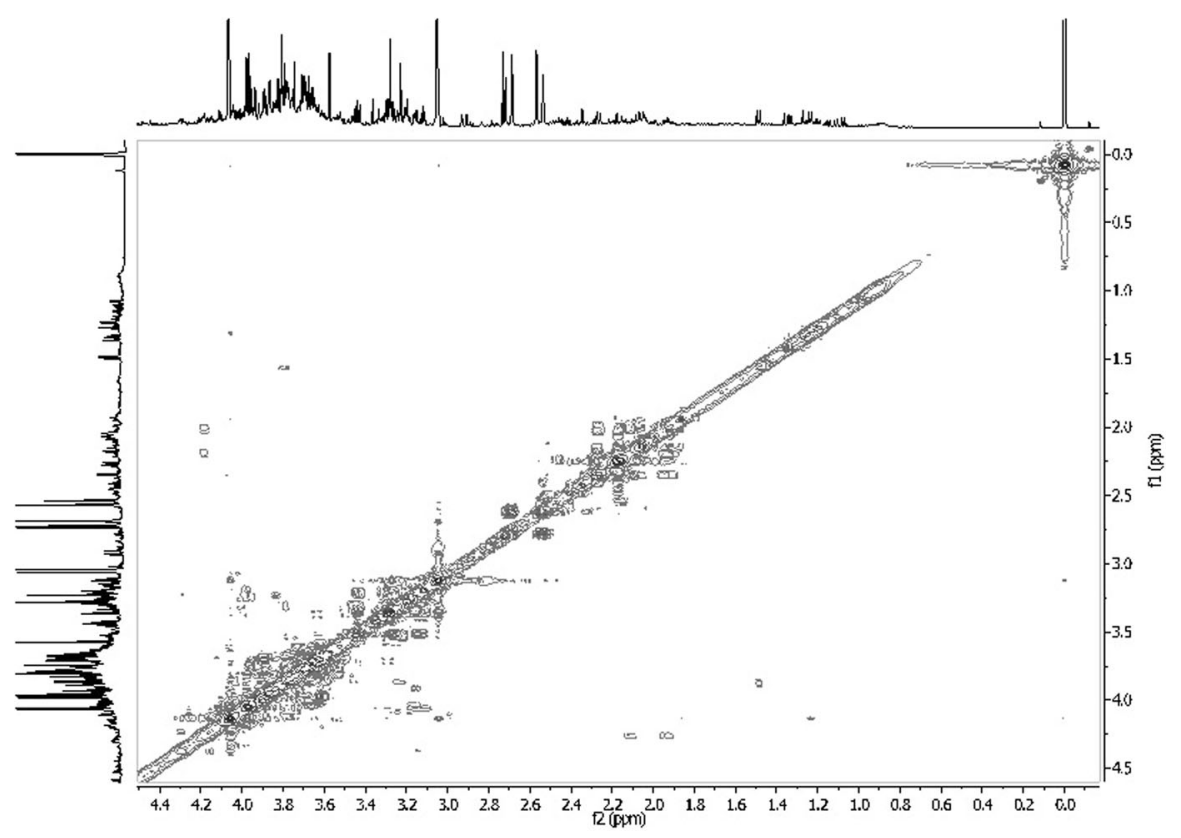

Fig. $10{ }^{1} \mathrm{H}^{1} \mathrm{H}$ COSY spectrum of human urine. Own researches 


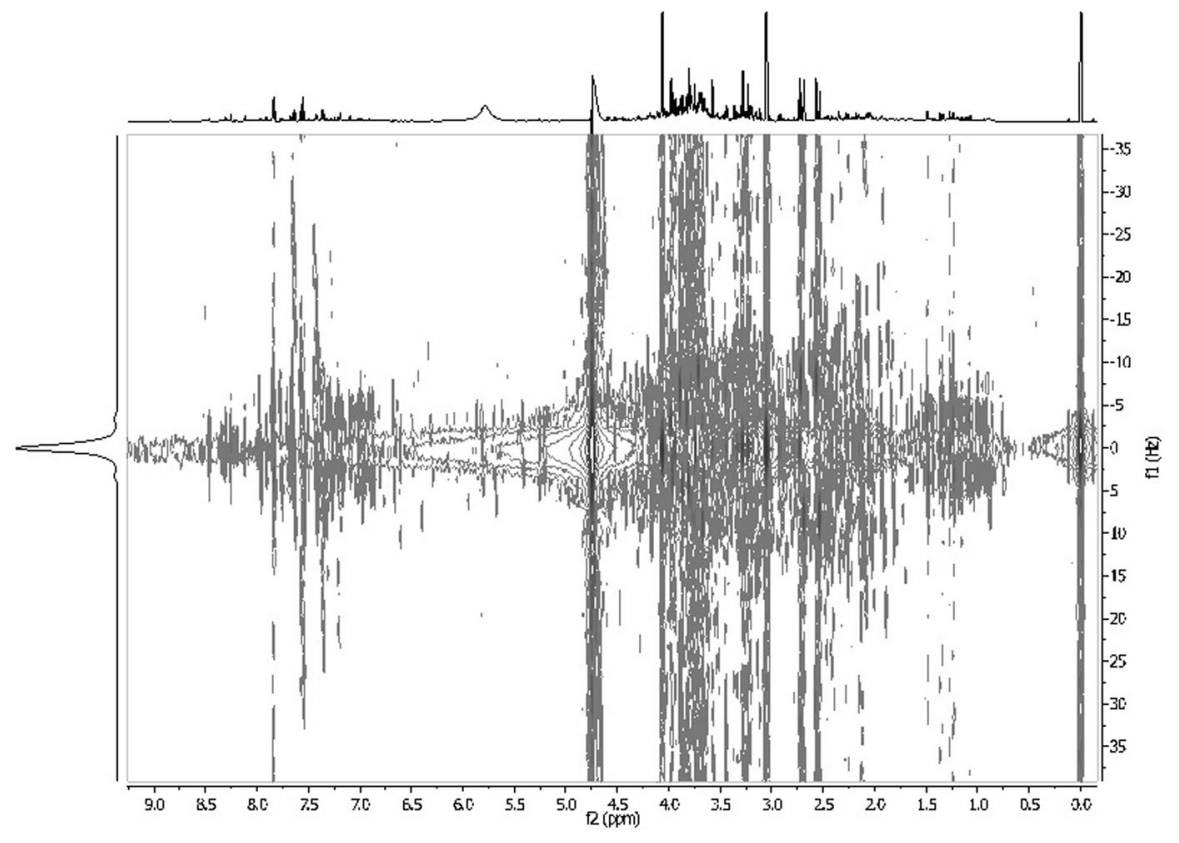

Fig. 11 JRES spectrum of human urine. Patient treated by cisplatin. Own researches

suppression techniques are mentioned. Moreover, using 2D techniques enables analyzing various biofluids and detecting small amount of numerous substances (Figs. 10, 11). Finally, solid-state techniques are non-destructive for biological samples and generally faster than techniques mentioned above. ${ }^{19} \mathrm{~F}$ NMR spectroscopy application in BNCT, gene therapy or potential drug screening is also pointed out. It is believed that due to these advantages and temporary development of spectroscopic techniques, they will be still used in metabolomic studies enabling detecting new substances with potential biomarker properties.

Acknowledgements This work was supported by the Poznan University of Medical Sciences No. 502-14-03308417-10167.

Open Access This article is distributed under the terms of the Creative Commons Attribution 4.0 International License (http://creativecommons.org/licenses/by/4.0/), which permits unrestricted use, distribution, and reproduction in any medium, provided you give appropriate credit to the original author(s) and the source, provide a link to the Creative Commons license, and indicate if changes were made.

\section{References}

1. K.R. Pomraning, S. Wei, S.A. Karagiosis, Y.-M. Kim, A.C. Dohnalkova, B.W. Arey, E.L. Bredeweg, G. Orr, T.O. Metz, S.E. Baker, PLoS One 10, 4 (2015)

2. L. Brennan, Prog. Nucl. Magn. Reson. Spectrosc. 83, 42-49 (2014)

3. N.J. Serkova, C.U. Niemann, Expert Rev. Mol. Diagn. 6(5), 717-731 (2006)

4. A. Zhang, H. Sun, P. Wang, Y. Han, X. Wang, Analyst 137, 293-300 (2012) 
5. https://www.ncsu.edu/chemistry/msf/pdf/IsotopicMass_NaturalAbundance.pdf (last log-on 12.07.2016)

6. S. Moco, J. Vervoort, S. Moco, R.J. Bino, R.C.H. De Vos, R. Bino, TrAC. Trends Anal. Chem. 26(9), 855-866 (2007)

7. N.V. Reo, Drug Chem. Toxicol. 25(4), 375-382 (2002)

8. R. Verpoorte, Y.H. Choi, H.K. Kim, Phytochem. Rev. 6, 3-14 (2007)

9. H.A. Scheidt, S. Schibur, A. Magalhães, E.R. de Azevedo, T.J. Bonagamba, O. Pascui, R. Schulz, D. Reichert, D. Huster, Biopolymers 93(6), 520-532 (2010)

10. G.S. Payne, H. Troy, S.J. Vaidya, J.R. Griffiths, M.O. Leach, Y.L. Chung, NMR Biomed. 19(5), 593-598 (2006)

11. J. Xu, P. Zhu, Z. Gan, N. Sahar, M. Tecklenburg, M.D. Morris, D.H. Kohn, A. Ramamoorthy, J. Am. Chem. Soc. 132(33), 11504-11509 (2010)

12. Z.-Z. Li, Q.-X. Guo, T. Ren, X.-Q. Zhu, Y-Ch. Liu, J. Inclusion. Phenom. Mol. Recogn. Chem. 15(1), 37-42 (1993)

13. R.M. Silverstein, F.X. Webster, D.J. Kiemle, Spektroskopowe Metody Identyfikacji Zwiazków Organicznych (Warszawa, Wydawnictwo Naukowe PWN, 2007), pp. 138-139

14. http://lipidlibrary.aocs.org/Analysis/content.cfm?ItemNumber=40256 (last log-on 12.07.2016)

15. D. Wishart, TrAC Trends Anal. Chem. 27(3), 228-237 (2007)

16. R. Schicho, R. Shaykhutdinov, J. Ngo, A. Nazyrova, C. Schneide, R. Panaccione, G.G. Kaplan, H.J. Vogel, M. Storr, J. Proteome. Res. 11(6), 3344-3457 (2012)

17. O. Risa, T.M. Melø, U. Sonnewald, NMR Biomed. 22(3), 266-271 (2009)

18. M.D. Cao, B. Sitter, T.F. Bathen, A. Bofin, P.E. Lønning, S. Lundgren, I.S. Gribbestad, NMR Biomed. 25(2), 369-378 (2012)

19. L. Da Silva, M. Godejohann, F.-P.J. Martin, S. Collino, A. Bürkle, M. Moreno-Villanueva, J. Bernhardt, O. Toussaint, B. Grubeck-Loebenstein, E.S. Gonos, E. Sikora, T. Grune, N. Breusing, C. Franceschi, A. Hervonen, M. Spraul, S. Moco, Anal. Chem. 85(12), 5801-5809 (2013)

20. T. Ye, C. Zheng, S. Zhang, G.A. Gowda, O. Vitek, D. Raftery, Anal. Chem. 84(2), 994-1002 (2012)

21. N. Araníbar, K.H. Ott, V. Roongta, L. Mueller, Anal. Biochem. 355(1), 62-70 (2006)

22. D.H. Zhou, C.M. Rienstra, J. Magn. Reson. 192(1), 167-172 (2008)

23. T. Ye, Ch. Zheng, S. Zhang, G.A. Nagana Gowgall, O. Vitek, D. Raftery, Anal. Chem. 84(2), 994-1002 (2012)

24. H.R. Tank, Y.L. Wang, J.K. Nicholson, Anal. Biochem. 325(2), 260-272 (2004)

25. X. Zhang, L. Xu, J. Shen, B. Cao, T. Cheng, T. Zhao, X. Liu, H. Zhang, Biochim. Biophys. Acta 1832(8), 1207-1216 (2013)

26. T.W.M. Fan, Prog. Nucl. Magn. Reson. Spectrosc. 28, 161-219 (1996)

27. A. Smolinska, J.M. Posma, L. Blanchet, K.A. Ampt, A. Atalli, T. Tuinstra, T. Luider, M. Doskocz, P.J. Michiels, F.C. Girard, L.M. Buydens, S.S. Wijmenga, Anal. Bioanal. Chem. 403(4), 947-959 (2012)

28. D.S. Wishart, M.J. Lewis, J.A. Morrissey, M.D. Flegel, K. Jeroncic, Y. Xiong, D. Cheng, R. Eisner, B. Gautam, D. Tzur, S. Sawhney, F. Bamforth, R. Greiner, L. Li, J. Chromatogr. B. Analyt. Technol. Biomed. Life Sci. 871(2), 164-173 (2008)

29. N. Psychogios, D.D. Hau, J. Peng, A.C. Guo, R. Mandal, S. Bouatra, I. Sinelnikov, R. Krishnamurthy, R. Eisner, B. Gautam, N. Young, J. Xia, C. Knox, E. Dong, P. Huang, Z. Hollander, T.L. Pedersen, S.R. Smith, F. Bamforth, R. Greiner, B. McManus, J.W. Newman, T. Goodfriend, D.S. Wishart, PLoS One 6(2), e16957 (2011)

30. S. Bouatra, F. Aziat, R. Mandal, A.C. Guo, M.R. Wilson, C. Knox, T.C. Bjorndahl, R. Krishnamurthy, F. Saleem, P. Liu, Z.T. Dame, J. Poelzer, J. Huynh, F.S. Yallou, N. Psychogios, E. Dong, R. Bogumil, C. Roehring, D.S. Wishart, PLoS One 8(9), e73076 (2013)

31. K.N. Patel, J.K. Patel, M.P. Patel, G.C. Rajput, H.A. Patel, Pharm. Methods 1(1), 2-13 (2010)

32. R.A. Shaykhutdinov, G.D. MacInnis, R. Dowlatabadi, A.M. Weljie, H.J. Vogel, Metabolomics 5(3), 307-317 (2009)

33. F. Weber, J. Böhme, H.A. Scheidt, W. Gründer, S. Rammelt, M. Hacker, M. Schulz-Siegmund, D. Huster, NMR Biomed. 25(3), 464-475 (2012)

34. A. Wong, P.M. Aguiar, D. Sakellariou, Magn. Reson. Med. 63(2), 269-274 (2010)

35. Y. Xi, J.S. de Ropp, M.R. Viant, D.L. Woodruff, P. Yu, Anal. Chim. Acta 614(2), 127-133 (2008)

36. A. Kaflak-Hachulska, A. Samoson, W. Kolodziejski, Calcif. Tissue Int. 73(5), 476-486 (2003)

37. Y. Wu, J.L. Ackerman, E.S. Strawich, C. Rey, H.M. Kim, M.J. Glimcher, Calcif. Tissue Int. 72(5), 610-626 (2003) 
38. A. Kaflak, D. Chmielewski, A. Górecki, A. Slosarczyk, W. Kolodziejski, Solid State Nucl. Magn. Reson. 29(4), 345-348 (2006)

39. A. Kaflak, W. Kolodziejski, Magn. Reson. Chem. 46(4), 335-341 (2008)

40. R.L. Johnson, K. Schmid, - Rohr. J. Magn. Reson. 239, 44-49 (2014)

41. K.H. Mroue, N. MacKinnon, J. Xu, P. Zhu, E. McNerny, D.H. Kohn, M.D. Morris, A. Ramamoorthy, J. Phys. Chem. B. 116(38), 11656-11661 (2012)

42. Y. Yang, L. Chen, H. Gao, D. Zeng, Y. Yue, M. Liu, H. Lei, F. Deng, C. Ye, Magn. Reson. Chem. 44(3), 263-268 (2006)

43. D. Zietkowski, R.L. Davidson, T.R. Eykyn, S.S. De Silva, N.M. Desouza, G.S. Payne, NMR Biomed. 23(4), 382-390 (2010)

44. O.M. Rooney, J. Troke, J.K. Nicholson, J.L. Griffin, Magn. Reson. Med. 50(5), 925-930 (2003)

45. D. Courtier-Murias, H. Farooq, H. Masoom, A. Botana, R. Soong, J.G. Longstaffe, M.J. Simpson, W.E. Maas, M. Fey, B. Andrew, J. Struppe, H. Hutchins, S. Krishnamurthy, R. Kumar, M. Monette, H.J. Stronks, A. Hume, A.J. Simpson, J. Magn. Reson. 217, 61-76 (2012)

46. S. Eriksson, S. Lasic, D. Topgaard, J. Magn. Reson. 226, 13-18 (2013)

47. P. Porcari, S. Capuani, E.D. Amore, M. Lecce, A. La Bella, F. Fasano, R. Campanella, L.M. Migneco, F.S. Pastore, B. Maraviglia, Phys. Med. Biol. 53(23), 6979-6989 (2008)

48. P. Porcari, S. Capuani, R. Campanella, A. La Bella, L.M. Migneco, B. Maraviglia, Phys. Med. Biol. 51(12), 3141-3154 (2006)

49. W. Cui, P. Otten, Y. Li, K.S. Koeneman, J. Yu, R.P. Mason, Magn. Reson. Med. 51, 616-620 (2004)

50. M.G. Boersma, I.P. Solyanikova, W.J.H. Van Berkel, J. Vervoort, I.M.C.M. Rietjens, J. Ind. Microbiol. Biotechnol. 26(1-2), 22-34 (2001)

51. M. Satake, B. Dmochowska, Y. Nishikawa, J. Madaj, J. Xue, Z. Guo, D.V. Reddy, P.L. Rinaldi, V.M. Monnier, Invest. Ophthalmol. Vis. Sci. 44(5), 2047-2058 (2003)

52. J. Ruiz-Cabello, B.P. Barnett, P.A. Bottomley, J.W.M. Bulte, NMR Biomed. 24(2), 114-129 (2011)

53. M. Veronesi, F. Giacomina, E. Romeo, B. Castellani, G. Ottonello, C. Lambruschini, G. Garau, R. Scarpelli, T. Bandiera, D. Piomelli, C. Dalvit, Anal. Biochem. 495, 52-59 (2016)

54. N. Aranibar, J.D. Vassallo, J. Rathmacher, S. Stryker, Y. Zhang, J. Dai, E.B. Janovitz, D. Robertson, M. Reily, L. Lowe-Krentz, L. Lehman-McKeeman, Anal. Biochem. 410(1), 84-91 (2011)

55. C.E. Garner, S.C. Sumner, J.G. Davis, J.P. Burgess, Y. Yueh, J. Demeter, Q. Zhan, J. Valentine, A.R. Jeffcoat, L.T. Burka, J.M. Mathews, Toxicol. Appl. Pharmacol. 215(1), 23-36 (2006)

56. S.H. Moolenaar, U.F. Engelke, N.G. Abeling, H. Mandel, M. Duran, R.A. Wevers, J. Inherit. Metab. Dis. 24(8), 843-850 (2001)

57. M.K. Engskog, O. Karlsson, J. Haglöf, A. Elmsjö, E. Brittebo, T. Arvidsson, C. Pettersson, Toxicology 312, 6-11 (2013)

58. E.G. Stanley, N.J. Bailey, M.E. Bollard, J.N. Haselden, C.J. Waterfield, E. Holmes, J.K. Nicholson, Anal. Biochem. 343(2), 195-202 (2005)

59. D. Misra, U. Bajpaic, Bull. Chem. Soc. Ethiop. 23(2), 211-221 (2009)

60. J.S. McKenzie, A.J. Charlton, J.A. Donarski, A.D. MacNicoll, J.C. Wilson, Metabolomics 6(4), 574-582 (2010)

61. H. Koskela, O. Heikkilä, I. Kilpeläinen, S. Heikkinen, J. Magn. Reson. 202(1), 24-33 (2010)

62. E. Appiah-Amponsah, K. Owusu-Sarfo, G.A. Gowda, T. Ye, D. Raftery, Metabolites 3, 575-591 (2013)

63. K. Hu, W.M. Westler, J.L. Markley, J. Am. Chem. Soc. 133(6), 1662-1665 (2011)

64. L. Zhao, H. Gao, F. Lian, X. Liu, Y. Zhao, D. Lin, Am. J. Physiol. Renal. Physiol. 300(4), F947-F956 (2011)

65. S. De Sanctis, W.M. Malloni, W. Kremer, A.M. Tomé, E.W. Lang, K.P. Neidig, H.R. Kalbitzer, J. Magn. Reson. 210(2), 177-183 (2011)

66. J.S. McKenzie, J.A. Donarski, J.C. Wilson, A.J. Charlton, Prog. Nucl. Magn. Reson. Spectrosc. 59(4), 336-539 (2011)

67. E. Martineau, I. Tea, S. Akoka, P. Giraudeau, NMR Biomed. 25(8), 985-992 (2012)

68. E. Martineau, P. Giraudeau, I. Tea, S. Akoka, J. Pharm. Biomed. Anal. 54(1), 252-257 (2011)

69. P. Sandusky, E. Appiah-Amponsah, D. Raftery, J. Biomol. NMR. 49(3-4), 281-290 (2011)

70. A.N. Lane, T.W.M. Fan, Metabolomics 3(2), 79-86 (2007)

71. J.C. Lindon, J.K. Nicholson, Annu. Rev. Anal. Chem. (Palo Alto Calif). 1, 45-69 (2008)

72. A. Beltran, M. Suarez, M.A. Rodríguez, M. Vinaixa, S. Samino, L. Arola, X. Correig, O. Yanes, Anal. Chem. 84(14), 5838-5844 (2012) 
73. R.K. Adosraku, G.T. Choi, V. Constantinou-Kokotos, M.M. Anderson, W.A. Gibbons, J. Lipid Res. 35, 1925-1931 (1994)

74. H.J. Schneider, U. Buchheit, N. Becker, G. Schmidt, U. Siehl 107(24), 7027-7039 (1985)

75. J.U. Thomsen, B. Meyer, J. Magn. Reson. 84(1), 212-217 (1989)

76. M.S. Hodavance, S.L. Ralston, I. Pelczer 387(2), 533-537 (2007) 